2008

\title{
Estimating Live Forest Carbon Dynamics with a Landsat-based Curve-fitting Approach
}

David O. Wallin

Western Washington University, david.wallin@wwu.edu

Todd A. Schroeder

Oregon State University

Andrew N. Gray

Forestry Sciences Laboratory (Corvallis, Or.)

Mark E. Harmon

Oregon State University

Warren B. Cohen

Forestry Sciences Laboratory (Corvallis, Or.)

Follow this and additional works at: https://cedar.wwu.edu/esci_facpubs

Part of the Environmental Sciences Commons

\section{Recommended Citation}

Wallin, David O.; Schroeder, Todd A.; Gray, Andrew N.; Harmon, Mark E.; and Cohen, Warren B., "Estimating Live Forest Carbon Dynamics with a Landsat-based Curve-fitting Approach" (2008). Environmental Sciences Faculty and Staff Publications. 15.

https://cedar.wwu.edu/esci_facpubs/15 


\title{
Estimating live forest carbon dynamics with a Landsat-based curve-fitting approach
}

\author{
Todd A. Schroeder ${ }^{\text {a* }}$, Andrew Gray ${ }^{\text {b }}$, Mark E. Harmon ${ }^{\text {a }}$, \\ David O. Wallin ${ }^{c}$, and Warren B. Cohen ${ }^{b}$ \\ ${ }^{a}$ College of Forestry, Department of Forest Science, 321 Richardson Hall, \\ Oregon State University, Corvallis, OR 97331, USA \\ ${ }^{\mathrm{b}}$ USDA Forest Service, Pacific Northwest Research Station, \\ Corvallis Forestry Sciences Laboratory, Corvallis, OR 97331, USA \\ ${ }^{\mathrm{c}}$ Department of Environmental Sciences, Huxley College of the Environment, \\ Western Washington University, Bellingham, WA, 98225, USA \\ *Corresponding Author \\ Department of Forest Resources Management, University of British Columbia, \\ 2424 Main Mall, Vancouver, BC, V6T 1Z4 \\ todd.schroeder@ubc.ca
}

\begin{abstract}
Direct estimation of aboveground biomass with spectral reflectance data has proven challenging for high biomass forests of the Pacific Northwestern United States. We present an alternative modeling strategy which uses Landsat's spatial, spectral and temporal characteristics to predict live forest carbon through integration of stand age and site index maps and locally calibrated Chapman-Richards curves. Predictions from the curve-fit model were evaluated at the local and landscape scales using two periods of field inventory data. At the pixel-level, the curve-fit model had large positive bias statistics and at the landscape scale over-predicted study area carbon for both inventory periods. Despite the over-estimation, the change in forest carbon estimated by the curve-fit model was well within the standard error of the inventory estimates. In addition to validating the curve-fit models carbon predictions we used Landsat data to evaluate the degree to which the field inventory plots captured the forest conditions of the study area. Landsat-based frequency histograms revealed the systematic sample of inventory plots effectively captured the broad range of forest conditions found in the study area, whereas stand age trajectories revealed a temporally punctuated shift in landuse which was not spectrally detected by the inventory sample.
\end{abstract}

Keywords: Live forest carbon, Forest inventory data, Site index, Chapman-Richards growth curves, Landsat time-series.

\section{INTRODUCTION}

As the global climate continues to warm [1] and countries around the world are tasked with estimating and reporting changes in terrestrial carbon stocks (e.g., Kyoto protocol), new and innovative techniques must be developed to accurately estimate forest carbon over vast spatial areas. Developing reliable estimates of terrestrial carbon flux is a difficult task as all the major terrestrial carbon pools exhibit considerable variability across space and time [2]. Terrestrial carbon fluxes cannot be measured directly at regional and global scales, thus we must rely on estimates derived from process [3,4] or accounting based models [5,6]. It is important that estimates of total carbon flux from terrestrial sources account not only for live carbon stocks, but also for other major component pools such as soils, woody detritus and forest products [7]. Accurately estimating the mass of living material is critical as it is often used to initialize component pools in regional scale carbon models [8]. Optical satellite imagery has been used to directly estimate amount and temporal variability in aboveground 
biomass $[9,10]$, however these methods are mostly sensitive to green foliage and show an asymptotic relationship with biomass [4]. Here we present an alternative method of using optical imagery to estimate live carbon stocks which attempts to minimize these limitations.

A key to accurately estimating live forest carbon is to account for the spatial effects of anthropogenic disturbance, land-use change and site productivity, which can vary considerably by ecoregion and forest type. Moderate resolution satellite data such as Landsat are particularly effective at tracking changes in land cover associated with harvest disturbances and land-use change [11] and have recently been used to characterize rates of early successional regrowth after clearcutting in western Oregon [12]. As forest growth extends beyond the stem exclusion phase of secondary succession, the spectral signal recorded by Landsat shows an asymptotic relationship with biomass [4], preventing growth characterization and limiting direct empirical modeling of biomass for mature forests $[10,13]$. Although Landsat is generally less effective at directly predicting biomass above 50 to 80 megagrams ( $\mathrm{Mg}$ ) per hectare (ha) [9], its spatial, spectral and temporal characteristics permit derivation of a variety of other useful products which can be utilized to help predict live forest carbon.

The growing legacy of temporal data available from Landsat (1972 - present) can be used in a "change-detection" context to accurately detect forest disturbances [14,15], especially in systems where disturbances are frequently the result of clearcut harvesting. If one takes advantage of the full historical legacy of Landsat [16], a variety of disturbance mapping techniques $[14,17,18]$ can be used to separate undisturbed forests from secondary forests. Once separated, an accurate age can be assigned to younger secondary forest stands which have been disturbed during the Landsat record $(\approx 30$-years $)$. When these Landsat-based secondary forest age maps are combined with maps of initial vegetation age (from Landsat) and site index, a modeling strategy can be employed to estimate live forest carbon at the pixel scale through the use of Chapman-Richards growth curves [19].

Site index curves and associated yield tables have long been used by foresters to predict the productive capacity of forests [20]. These curves are also an effective way of diagramming temporal patterns of forest productivity, especially as they relate to carbon sequestration at various spatial scales [21]. In the Pacific Northwest, long term patterns of forest succession are generally well understood [22] thus we can reasonably construct a predictive model using a meta-modeling approach [23]. This involves using a detailed standlevel model to parameterize a simpler set of functions which can more efficiently be applied to a broader landscape. The approach (referred to here as curve-fit), assumes a single successional pathway through Douglas-fir, the most predominant forest species in the study area. Although this is a major simplifying assumption, the method's strength lies in its ability to accurately account and spatially track the impact of forest harvesting on the carbon budget. Once calibrated, growth curves can easily be incorporated into more comprehensive models which track carbon through a variety of pools and pathways. In addition, curves offer the potential to be applied in a less computationally intensive manner as some process driven models and offer potential to estimate more reasonably the upper bounds of carbon storage in mature forests.

This curve-fitting approach to estimating live forest carbon has been previously utilized within the framework of a comprehensive model for estimating carbon flux from temperate coniferous forests of the Pacific Northwestern United States referred to as Landcarb [5,7,24]. Although live forest carbon estimates from the curve-fit model have been shown to accurately reflect county level harvest statistics from the Oregon Department of Forestry (ODF) [24], a direct comparison with field inventory data would offer a more comprehensive evaluation of model performance. Inventory data such as those collected by United States Forest Service Forest Inventory and Analysis (FIA) program are generally considered one of the most robust ways of estimating live carbon dynamics in relation to land-use change and interannual variation in climate. For this to be true however, it is necessary that the sample of plots be 
carefully laid out in order to capture the full range of forested conditions and land-use patterns found in the study area. As inventory protocols change over time it is important to determine the extent to which the full range of forest conditions are captured by the systematic sample of ground plots.

Satellite sensors such as Landsat offer both a synoptic view of the landscape, as well as the spectral capacity to characterize forests in terms of structure and cover. Vegetation indices such as the Tasseled Cap wetness [25] have been shown to be important indicators of maturity and structure in closed canopy forests and are relatively insensitive to cosine of the incidence angle effects $[26,27]$. The consistent and predictable spectral response of vegetation indices to various stages of forest structural development make them particularly useful for evaluating the range of forested conditions captured by the inventory sample. Vegetation indices can be examined at one point in time or as a time-series to detect areas on the landscape which might be deviating away from the normal course of forest succession. In heavily forested areas, large spectral shifts are often the result of permanent forest to non-forest land-use conversion.

In this paper we address the following two objectives. First, to evaluate predictions of live forest carbon produced by the curve-fit model for image dates corresponding to two FIA field inventories. The predictions of live forest carbon (including foliage, branch, bark, bole, and coarse roots) are evaluated using inventory data at the local and landscape scales. At the local scale, we evaluate pixel-level estimates of forest carbon from the curve-fit model using scatter plots and regression diagnostics for two forested ecoregions with known differences in productivity. At the landscape scale, study area forest carbon and net carbon flux (i.e., difference between inventory periods) estimated with field plots are compared with the curvefit models map-based estimates. Second, Landsat tasseled cap wetness is used as a proxy measure to investigate the degree to which the FIA plot sample captures the spectral variation in forest conditions found in the study area. At two different points in time (representing two FIA inventory periods) we compare relative frequency histograms of wetness developed from the full study area and for the area directly sampled by the inventory plots. In addition, we use a chronosequence approach (i.e., space for time) to construct wetness trajectories using stand ages derived from the field inventory plots and from the remote sensing based changedetection maps. The wetness trajectories are examined for noticeable spectral shifts away from normal forest development which might indicate permanent forest to non-forest land-use change.

\section{METHODS}

\subsection{Study area}

The study area is comprised of a 2,140,557 ha forest area located in western Oregon, USA. The study area (Figure 1) covers portions of two forested ecoregions (level III, [28]), which are described by Franklin and Dyrness [29] as the Coast Range Province (CRP) and the Western Cascades Province (WCP). In the western portion of the CRP cool, wet conditions along the coast create a narrow, one to two kilometer wide Sitka spruce (Picea sitchensis (Bong.) Carr.) zone. The rest of the CRP and the majority of the WCP are dominated by conifers common to the Douglas-fir (Pseudotsuga menziesii (Mirb.) Franco)/western hemlock (Tsuga heterophylla (Raf.) Sarg.) association, although hardwood species such as red alder (Alnus rubra Bong.), bigleaf maple (Acer macrophyllum Pursh), and Oregon white oak (Quercus garryana Dougl. Ex Hook.) can dominate moist riparian areas and dry valley margins. The climate of the Pacific Northwest is typified by warm, dry summers and mild, wet winters. The study area encompasses a wide range of elevations, yielding strong physical and climatic gradients. Climatic differences, in concert with differences in elevation and geology yield a wide array of growing conditions within the study area. The prevailing winds and rugged topography generally yield warmer, wetter conditions in the CRP and colder and 
drier conditions in the WCP. The combination of these geographic characteristics, in concert with impacts from forest management, have led to previous findings that the CRP typically supports faster regrowth after clearcut harvesting $[12,30]$.

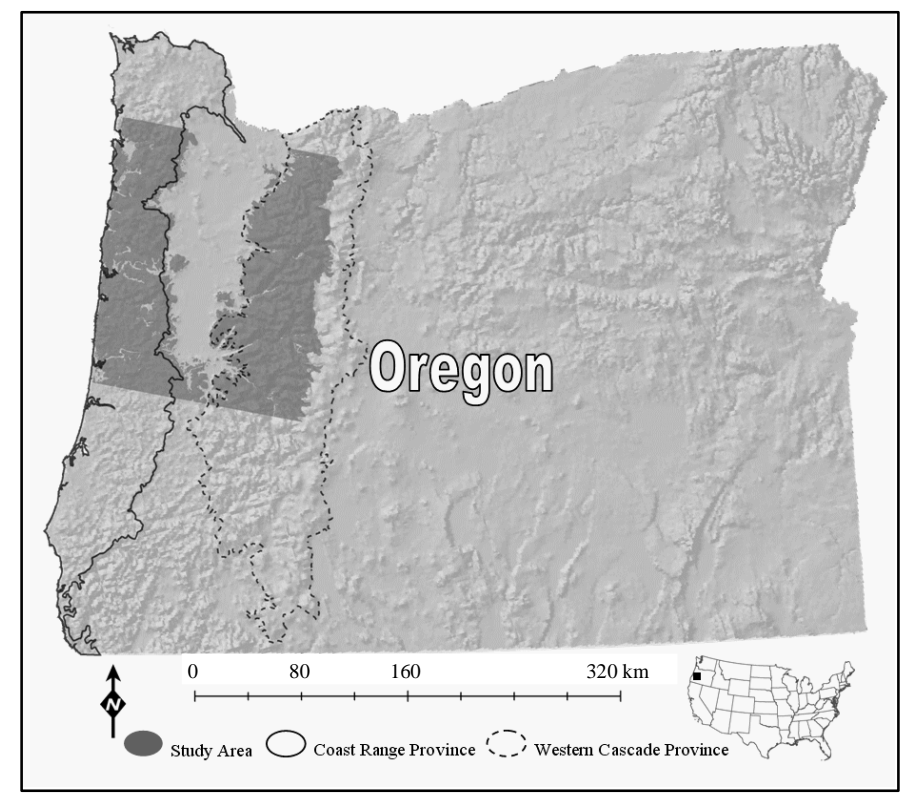

Fig. 1 . The $2,140,557$ ha forested study area in western Oregon, USA.

\subsection{Data}

\subsubsection{Forest inventory data}

FIA has been collecting field measurements of forest attributes in the United States since 1928 [31]. The FIA inventory follows a two-phase post-stratification process to reduce the variance of inventory estimates [32]. In the first phase, a grid of sample points is classified using aerial photographs or maps generated from Landsat imagery. In the second phase, a systematic subset of these grid points is selected and measured by a trained field crew and marked for remeasurement in future inventories. Currently the FIA program implements an annualized sampling scheme (referred to here as annual inventory) where $10 \%$ of field plots (for western states) are systematically measured and reported each year, on a 10-year cycle. Previously all plots in a state were measured within a few years and remeasured approximately every 10 to 15 years (referred to here as periodic inventory).

There are several differences between the periodic (data collected between 1993 - 1997) and annual (data collected between 2000 - 2005) FIA inventories conducted in Oregon, mostly resulting from the switch in 2000 to a nationally consistent inventory design that now collects data on a systematic sample (10\%) of plots within each western state each year. Other differences include plot layout configuration (shape and size), number of measured subplots (periodic $=5$, annual $=4$ ), and variable vs. fixed radius subplots. In addition, during the periodic inventory FIA only collected plot data on privately owned forest lands in Oregon, as opposed to the current annual inventory which now collects data on both private and public forest lands. To compensate for this difference we make use of data collected on public lands by the U.S. Forest Service Region 6 (R6) and Bureau of Land Management (BLM). Data collected by all three land management agencies were compiled by the Pacific Northwest FIA 
program into an Integrated Database (IDB) which uses common formats, definitions, measurement units, column names and table structures [33]. We refer to this data set as IDB periodic and the annual data set collected solely by FIA as FIA annual.

Subplots are systematically located with respect to the sample grid point (plot center) and may encompass different land cover conditions (e.g. different forest types, non-forest, water). Thus some plots may consist entirely of a single condition, whereas others could have up to 5 different conditions distributed across portions of the subplots. To minimize spectral heterogeneity it is not uncommon that only single condition plots are considered when FIA data are used to directly model forest attributes with remotely sensed imagery [12,34]. Others have used an approach where all condition class plots are used and a screening process (either visual or statistical) is used to discard plots that are assessed as spectral outliers [35]. Here we use all condition class plots to validate carbon at both the pixel and landscape scales. Although actual FIA plot coordinates are not publicly available, we utilized them here as this study was sponsored by the Pacific Northwest FIA program. To minimize the impact from any remaining image to plot misregistration we used the mean of a pixel-mask matching the size, shape and alignment of the field plots to extract values from the carbon maps and wetness images.

\subsubsection{Stand age maps}

Spatial representation of stand age is required as an input layer to the curve-fit model. The process of deriving stand age maps for our western Oregon study area is adapted from the procedure used within the Landcarb modeling framework [5]. Briefly the process combines a Landsat vegetation age map (based on separate classifications of percent green vegetation cover, percent conifer/hardwood cover and stand age) [36] with a Landsat based stand disturbance map of timber harvests and wildfires (derived via image differencing in roughly 5 $( \pm 2)$ year intervals) originally produced for western Oregon through 1995 [11]; updated with similar change detection techniques through 2002 [37] and again through 2004 [38].

Three vegetation maps (percent green vegetation cover, percent conifer/hardwood cover, and a 3 class (young, mature and old-growth) forest stand age map) [36] were combined to form seven broad classes of vegetation defined as open $(<30 \%$ green vegetation cover $(\mathrm{GVC})$ ), semi-open $(30-70 \% \mathrm{GVC})$, broadleaf (>70\% broadleaf cover $(\mathrm{BC}))$, mixed $(>70 \%$ $\mathrm{GVC},<70 \% \mathrm{BC}$ and $<70 \%$ conifer cover $(\mathrm{CC})$ ), young conifer $(>70 \% \mathrm{CC},<80$ years), mature conifer (>70\% CC, 80-200 years) and old-growth conifer (>70\% CC, > 200 years). Approximate "structural" age class bins were assigned to the above classes resulting in age class bins of 1-10 years (open), 11-20 years (semi-open), 21-30 years (broadleaf/mixed), 3180 years (young), 80-200 years (mature) and > 200 years (old-growth). For modeling purposes, we assumed the median age of each age class bin was the current stand age in the 1988 vegetation map (old-growth was assigned an age of 225). The stand disturbance map was then used to mask out all areas of known disturbance (fire and timber harvest) occurring between 1972 and our two image dates. The stand age for these pixels was taken to be the median year of the mapped disturbance interval. For all undisturbed areas, the age from the 1988 vegetation map was increased by 7 or 16 years to estimate the stand age at the time of our two image dates (1995 and 2004). For example, when creating the 2004 age map all areas of known disturbance were masked from the 1998 vegetation map. If a pixel was labeled as disturbed between 1984 and 1988 its median year of disturbance (i.e., 1986) was subtracted from 2004, yielding an estimated stand age of 18 years. For all unmasked areas (i.e., forest undisturbed since 1988), the age from the 1988 vegetation map was increased by 16 years to estimate its stand age at the point of the 2004 image date. So if a pixel was labeled as "open" in 1988, its stand age was estimated from the median of its age bin in 1988 (i.e., 5) plus 16 years $(2004-1988=16)$, yielding an estimated stand age of 21 years $(5+16=21)$. This 
procedure was used to "spin-up" an estimated stand age map for the 1995 and 2004 image dates.

\subsubsection{Site index}

To account for variability in forest growth due to climate and soils (i.e., potential forest productivity) a site index map is used as input to the curve-fit model. Timber companies often keep local data and spatial records of productivity for their land holdings, but consistent regional data are not widely available [39]. The only known map of site index available for western Oregon and Washington was produced in 1949 by Isaac [40]. Produced using field survey and elevation data the map categorizes site index into five classes (site index $1=$ most productive, site index 5 = least productive) which previously have been shown to correspond with known relationships of forest productivity in the region [24]. As this was the site index map used in the original work involving the curve-fit model [5,7], we used it here for further evaluation.

\subsubsection{Landsat imagery}

Two cloud-free, near-anniversary Landsat-5 TM (WRS-2, path 46, row 29) images were used in this study (8/19/1995 and 8/11/2004). Both images were cross-calibrated as part of a 19 image time-series [41] which used statistically selected pseudo-invariant features [42] to relatively normalize all images to an atmospherically corrected reference image (corrected with 6S, [43]). The approach, referred to as absolute-normalization effectively normalized all images to a common radiometric scale (across all images $<0.025$ RMSE) while simultaneously correcting for atmospheric and sun-sensor view-angle effects. Given similar radiometry after normalization, the Landsat wetness frequency histograms and stand age trajectories derived from the 1995 and 2004 image dates can be directly compared to evaluate the representativeness of the inventory sample.

\subsubsection{Inventory carbon estimation}

\subsubsection{Per-pixel carbon}

Data from both the FIA annual and IDB periodic databases were used to validate both pixellevel and study area predictions of live forest carbon produced by the curve-fit model. For the pixel-level validation, raw tree data for trees $>2.5$ centimeters $(\mathrm{cm})$ diameter at breast height (DBH) from both FIA inventories were converted to aboveground biomass (including branches, bole, bark and foliage) using national-scale allometric equations [44] of the form of Eq. 1,

$$
b m=\operatorname{Exp}\left(\beta_{0}+\beta_{1} \ln d b h\right)
$$

where bm is biomass per tree in kilograms $(\mathrm{kg})$ per tree, dbh is diameter at breast height (in $\mathrm{cm})$, Exp is an exponential function, $\ln$ is natural $\log$ base "e", and $\beta_{0}$ and $\beta_{1}$ are parameters based on 10 general species groups (for species group parameters see [44], Table 4)). We favor the use of national scale equations as they are developed over broad areas using a large numbers of trees. Coarse root biomass was estimated for trees $>2.5 \mathrm{~cm} \mathrm{DBH}$ using Eq. 2 [44],

$$
\text { ratio }=\operatorname{Exp}\left(\beta_{0}+\frac{\beta_{1}}{d b h}\right)
$$


where ratio is the coarse root ratio to total aboveground biomass from Eq. 1 (for parameters see [44]). For each plot an adjustment was made to account for seedling biomass based on group count data for trees $<2.5 \mathrm{~cm} \mathrm{DBH}$. Tree biomass was expanded to represent plot area (i.e., multiplied by trees per hectare) and summed resulting in a plot estimate of biomass in $\mathrm{kg}$ $\mathrm{ha}^{-1}$. Plot biomass was then converted from $\mathrm{kg} \mathrm{ha}^{-1}$ to $\mathrm{Mg} \mathrm{C} \mathrm{ha}^{-1}$ assuming $50 \%$ of living biomass is carbon [45].

\subsubsection{Study area carbon}

To calculate study area live forest carbon, the tree-level data were converted to aboveground biomass as stated above and then expanded by the number of hectares each plot represents in the study area. To derive the area each plot represents in the study area we adjusted the number of hectares each plot represents in each inventory using Eq. 3,

$$
\text { Adj Fac }=\frac{\text { Study area } h a}{\text { Inventory } h a},
$$

where Adj Fac is the adjustment factor applied to the plot level expansion factor, Study area ha is the total number of hectares in the study area and Inventory ha is the total number of hectares each collection of plots represents in its respective inventory. After applying the adjustment factor (0.9956 for IDB periodic, 0.9533 for FIA annual) the resulting numbers were used to expand the per plot biomass estimates for each inventory period, which were then summed across plots to yield an estimate of live forest carbon for the study area (reported in teragrams $\mathrm{Tg}$ ).

\subsubsection{Curve-fit carbon model}

Using a look-up table approach [46], the curve-fit model uses a set of Chapman-Richards growth curves along with stand age and site index maps to estimate live forest carbon (including foliage, branches, bole, and coarse roots). The curves are defined using Eq. 4,

$$
L I V E=\operatorname{LIVEMAX} *\left(1-e^{\left(-B_{1} * A G E\right)}\right)^{B_{2}},
$$

where LIVE is the live forest carbon store in $\mathrm{Mg} \mathrm{C} \mathrm{ha}^{-1}$, LIVEMAX is the maximum live forest carbon store, $\mathrm{B}_{1}$ is the rate that determines how quickly live forest carbon approaches the maximum, $\mathrm{B}_{2}$ determines how long plant production lags behind the maximum rate, and AGE is the number of years since disturbance. The curve parameters (Table 1) are taken from STANDCARB [47], which is a stand-level model that integrates effects of site condition, disturbance severity, tree re-establishment and species composition on forest growth. The maximum live carbon storage in aboveground and belowground pools was determined from past field studies conducted within the region $[48,49,50]$. The curves, parameterized using yield tables published for Douglas-fir [51] are presented in Figure 2. Live forest carbon maps were produced for both the 1995 and 2004 image dates.

\subsubsection{Carbon model validation}

\subsubsection{Per-pixel carbon}

To evaluate local scale performance of the curve-fit model we directly compared its predictions of live forest carbon to those estimated with the FIA data. We used all multiple condition class plots with measured trees, resulting in 1,180 IDB periodic $(n=404$ CRP, 
Table 1. Equation parameters defining Chapman-Richards growth curves in Fig. 2.

\begin{tabular}{cccc}
\hline Site index & Live Max $\left(\mathrm{Mg} \mathrm{C} \mathrm{ha}^{-1}\right)$ & $\mathrm{B}^{1}$ & $\mathrm{~B}^{2}$ \\
\hline 1 & 650 & 0.021 & 1.98 \\
2 & 570 & 0.021 & 1.97 \\
3 & 460 & 0.021 & 1.96 \\
4 & 310 & 0.020 & 1.92 \\
5 & 230 & 0.020 & 1.88 \\
\hline
\end{tabular}

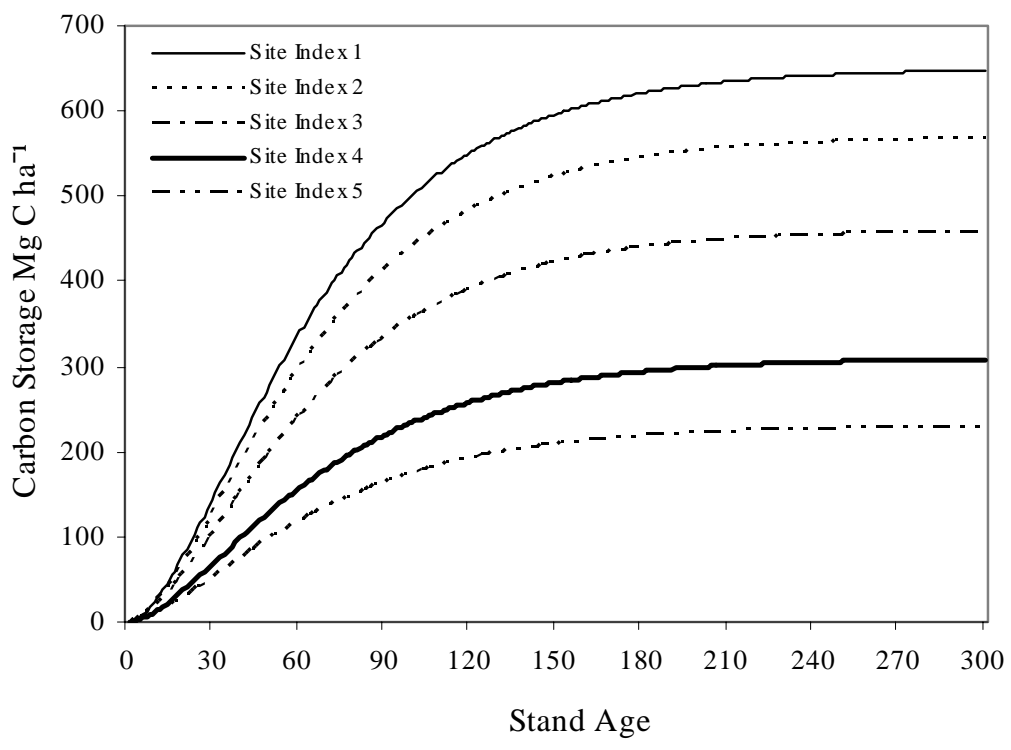

Fig.2. Chapman-Richards growth curves used to predict live forest carbon.

$\mathrm{n}=776 \mathrm{WCP})$ and 403 FIA annual plots $(\mathrm{n}=165 \mathrm{CRP}, \mathrm{n}=238 \mathrm{WCP})$ available for analysis Fewer plots are available for the annual FIA inventory as only 5 years of data $(50 \%)$ had been collected since the inception of the new annualized FIA inventory in 2001. For each sample plot (using the confidential FIA coordinates), we derived the pixel-level estimates of carbon using the mean value of one of two pixel masks (1.22-pixel mask for the FIA IDB periodic plots; and 2. 13-pixel mask for FIA annual plots, BLM and R6 plots) which were designed to reflect the various sizes, shapes and coordinate measurement locations of the field plots used in the two inventories. Scatter plots for both image dates were developed by ecoregion using the predicted (from the curve-fit model) and observed estimates (from FIA data) of live forest carbon. Descriptive statistics (i.e., minimum (min), maximum (max), mean and standard deviation (stdev)) and regression diagnostics (bias (mean of predicted - mean of observed), root mean square error (RMSE), variance ratio (VR = standard deviation of predicted / standard deviation of observed)) are used to evaluate the carbon models capacity to locally predict forest carbon in each ecoregion. A small portion of the study area does not fall into either of the forested ecoregions used in the per pixel validation. Thus, for each inventory, the number of plots used in the per pixel validation are slightly less than the total number of plots used to calculate the landscape scale estimates of live forest carbon. 


\subsubsection{Study area carbon}

To evaluate the landscape scale performance of the curve-fit model we directly compared the map-based predictions of study area live forest carbon to those estimated with all the multiple condition class plots from each FIA inventory period $(n=1,450$ for IDB periodic, $n=432$ for FIA annual). For each inventory period the plots were used to calculate study area live forest carbon (in Tg), as well as associated standard errors (Bechtold and Patterson 2005). For the curve-fit model, study area live forest carbon was calculated for both image dates by summarizing the map-based predictions using Eq. 5,

$$
\text { Study } \left.C=\sum_{A B}\left(A B_{P}\right) *\left(A B_{C} * 0.0625\right)\right)
$$

where Study $\mathrm{C}$ is the estimated study area live forest carbon (in $\mathrm{Tg}$ ), $A B$ represents the age class bins from the stand age maps, $A B_{P}$ is the number of pixels in each age class bin, $A B_{C}$ is the live forest carbon value in $\mathrm{Mg} \mathrm{C} \mathrm{ha}{ }^{-1}$ of each age class bin, and 0.0625 is the number of ha represented by each $25 \times 25$ meter Landsat pixel. In addition to study area live forest carbon, we also differenced the respective map and inventory-based estimates to report the flux of live forest carbon occurring between the near decadal point-in-time estimates. Differences are reported in absolute values (in Tg), relative percentages (i.e., \% of initial value) and amount of forest carbon sequestered on a per year basis (based on 9 years between point-in-time estimates, reported in $\mathrm{Mg} \mathrm{C}$ ha ${ }^{-1}$ ).

\subsubsection{Landsat wetness}

Tasseled cap wetness was calculated for both the 1995 and 2004 Landsat images using the reflectance based equations of Crist [52]. We used wetness as a proxy measure to evaluate the extent to which the FIA sample plots captured the range of forested conditions found in the study area at the time of each inventory period. This was accomplished by comparing relative frequency histograms of the wetness values observed across the full study area to those captured by the inventory plots $(n=1,450$ for periodic, $n=432$ for annual). The relative frequency histograms were constructed for both image dates using the mean wetness values from each plots respective pixel mask (described above).

In addition to the frequency histograms, we also developed wetness trajectories using a chronosequence approach where wetness values were plotted according to stand age taken from the Landsat maps and from the field measured inventory plots. Since the two stand age maps were generated to represent forest structural ages at different points in time (e.g., age 12 in 1995 map is age 21 in 2004 map) we summarized wetness from both age maps in one trajectory. For the inventory-based trajectory, we combined stand age from both FIA inventories into the same age bins used in the stand age maps. In all the trajectories, wetness is reported as average per age bin (error bars are standard deviations). Because the study area is heavily forested and since wetness responds predictably to forest growth, the wetness trajectories should track along a predictable spectral pathway as the forest grows over time. Forest stands not progressing along a normal tract of forest development will cause a pronounced spectral shift in the wetness trajectory, indicating possible forest to non-forest land-use changes that might permanently impact the carbon cycle. 


\section{RESULTS}

\subsection{Per-pixel carbon validation}

The results indicate that across ecoregions and inventory periods the mean curve-fit predictions of per-pixel live forest carbon are in all cases greater than the mean estimates of the inventory data (Table 2). The standard deviations of the curve-fit predictions were similar across ecoregions and inventory periods and were observed to be within $\pm 7 \mathrm{Mg} \mathrm{C}^{-1}$ of the standard deviations of the FIA plot estimates. The results indicate (Table 2) that across inventory periods the curve-fit model more accurately predicts (i.e., higher correlation and lower RMSE) per-pixel live forest carbon in the CRP than in the WCP. The large positive bias statistics suggests the curve-fit model consistently over predicts per-pixel live forest carbon in both ecoregions. The variance ratio reveals an inconsistent pattern regarding the amount of observed variation preserved in the curve-fit predictions. Scatter plots of predicted (from the curve-fit model) versus observed (from FIA plot data) per-pixel live forest carbon (Figure 3) show an over-prediction of low and mid-range values and under-prediction of high values.

Table 2. Descriptive statistics and regression diagnostics for pixel-level forest carbon validation.

\begin{tabular}{|c|c|c|c|c|c|c|c|c|c|c|}
\hline 1995 & $\mathrm{n}$ & $\operatorname{Min}^{*}$ & $\operatorname{Max}^{*}$ & Mean* & Stdev* & Bias & RMSE $^{*}$ & VR & $\mathrm{r}$ & $\mathrm{R}^{2}$ \\
\hline CRP & 404 & & & & & 41.21 & 116.03 & 0.95 & 0.67 & 0.45 \\
\hline FIA Plot & & 0.02 & 633.71 & 182.83 & 136.91 & & & & & \\
\hline Curve-fit & & 0.73 & 541.23 & 224.04 & 130.08 & & & & & \\
\hline WCP & 776 & & & & & 34.28 & 142.89 & 1.01 & 0.50 & 0.25 \\
\hline IDB Plot & & 0.01 & 875.28 & 190.43 & 137.90 & & & & & \\
\hline Curve-fit & & 1.00 & 628.15 & 224.71 & 139.75 & & & & & \\
\hline 2004 & $\mathrm{n}$ & $\operatorname{Min}^{*}$ & $\operatorname{Max}^{*}$ & Mean* & Stdev* & Bias & RMSE $^{*}$ & VR & $\mathrm{r}$ & $\mathrm{R}^{2}$ \\
\hline CRP & 165 & & & & & 52.81 & 126.87 & 1.06 & 0.58 & 0.33 \\
\hline FIA Plot & & 0.01 & 654.09 & 156.08 & 121.80 & & & & & \\
\hline Curve-fit & & 0.08 & 518.00 & 208.88 & 129.44 & & & & & \\
\hline WCP & 238 & & & & & 45.75 & 135.29 & 0.94 & 0.57 & 0.32 \\
\hline FIA Plot & & 0.03 & 728.24 & 179.73 & 141.22 & & & & & \\
\hline Curve-fit & & 1.00 & 632.54 & 225.48 & 132.14 & & & & & \\
\hline
\end{tabular}

\subsection{Study area carbon validation}

Landscape scale performance of the curve-fit model is based on the predictions of study area live forest carbon found in Table 3. For both inventory periods, the curve-fit model estimated on average $138.32 \mathrm{Tg}$ more live forest carbon than was estimated with the inventory plot data $(+133.76 \mathrm{Tg}$ in $1995,+142.88 \mathrm{Tg}$ in 2004). When considered in absolute terms, the net flux (i.e., difference in inventory estimates) of live forest carbon predicted by the curve-fit model is $9.12 \mathrm{Tg}$ more than estimates derived with the inventory data. However, in relative terms the flux estimate derived with the curve-fit model is nearly the same as the FIA estimate $(-0.18 \%)$. The results show that the flux of live forest carbon estimated by the curve-fit model is well within the standard error calculated for the inventory estimates (Table 3). It should be noted that the higher standard error reported for the FIA annual inventory results from fewer plots being available from which to calculate live forest carbon. On a per year basis, the curve-fit 
model predicted a larger carbon sink $\left(0.47 \mathrm{Mg} \mathrm{C} \mathrm{ha}^{-1} / \mathrm{yr}\right)$ than estimated with the inventory data.
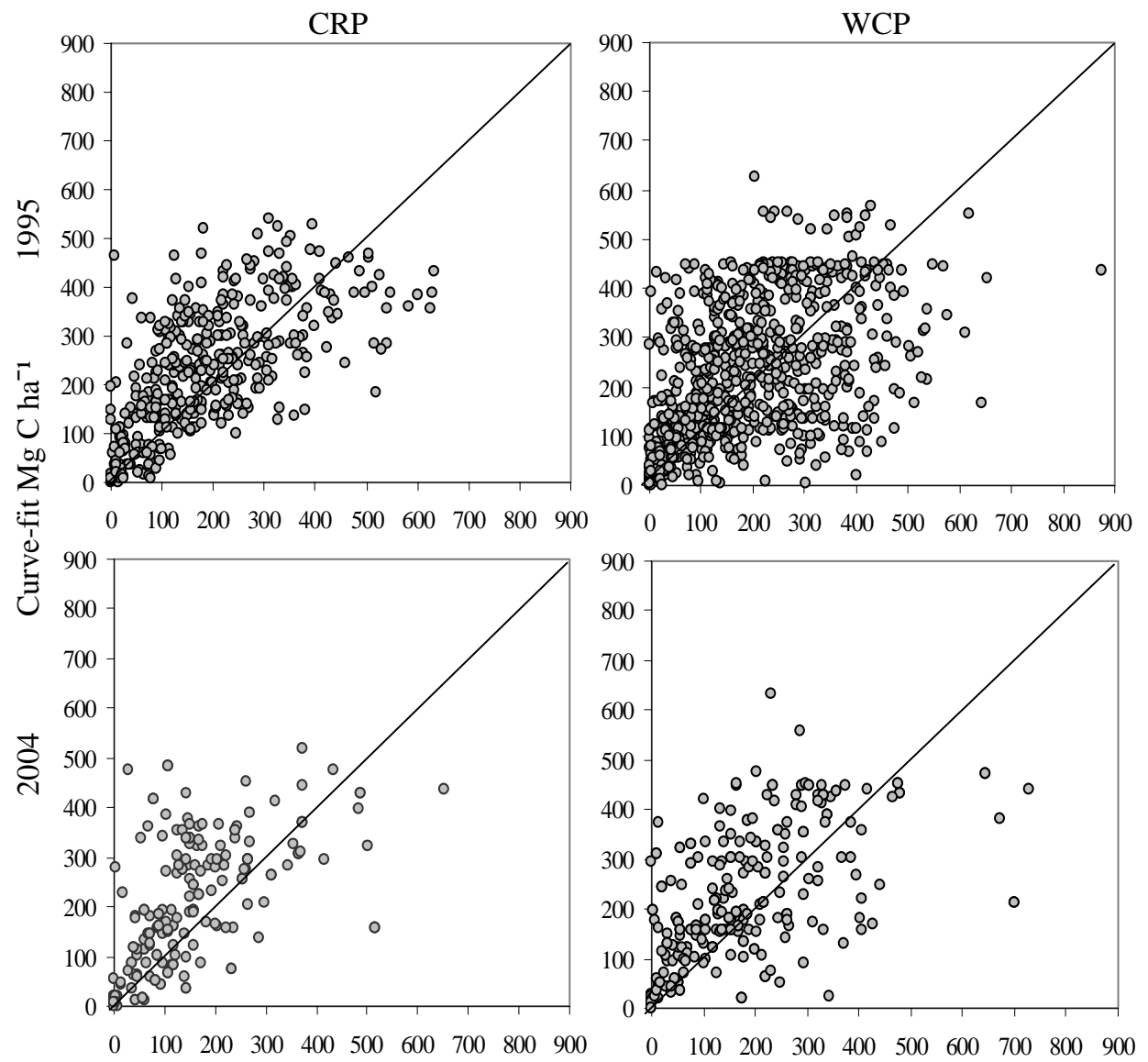

Plot $\mathrm{Mg} \mathrm{C} \mathrm{ha-1}$

Fig. 3. Scatter plots of per-pixel observed (from inventory plots) versus predicted (from curve-fit model) live forest carbon by ecoregion and image date. $\mathrm{CRP}=$ Coast Range Province, $\mathrm{WCP}=$ Western Cascade Province.

Table 3. Study area live forest carbon validation statistics.

\begin{tabular}{lcccccc}
\hline & $\mathrm{n}$ & Total C** & SE** $^{* *}$ & Absolute** & Relative & Per Year* \\
\hline \multicolumn{1}{c}{ Map } & & & & 31.48 & $7.22 \%$ & -1.63 \\
1995 Curve-fit & - & 435.94 & - & & & \\
2004 Curve-fit & - & 467.42 & - & & & \\
\hline \multicolumn{1}{c}{ Plot } & & & & 22.36 & $7.40 \%$ & -1.16 \\
IDB Periodic & 1,450 & 302.18 & 7.98 & & & \\
FIA Annual & 432 & 324.54 & 15.71 & & & \\
\hline *units = Mg C ha ${ }^{-1}$ & & & & & & \\
$* *$ units = Tg C \\
negative sign denotes C sink
\end{tabular}




\subsection{Landsat wetness histograms and trajectories}

To gauge a general sense of the forest conditions captured by the inventory sample we derived relative frequency histograms of Landsat wetness for the full forested study area and for the inventory plots. The relative histograms (not presented) confirm that the inventory plots effectively captures the full range of wetness values observed in the study area. To get a better sense of how well the inventory sample captures changes in forest condition over time we examined wetness trajectories developed using a chronosequence approach. Plotted by ecoregion, the wetness trajectories (error bars are standard deviations) developed using both the map and inventory-based age classes are found in Figure 4.
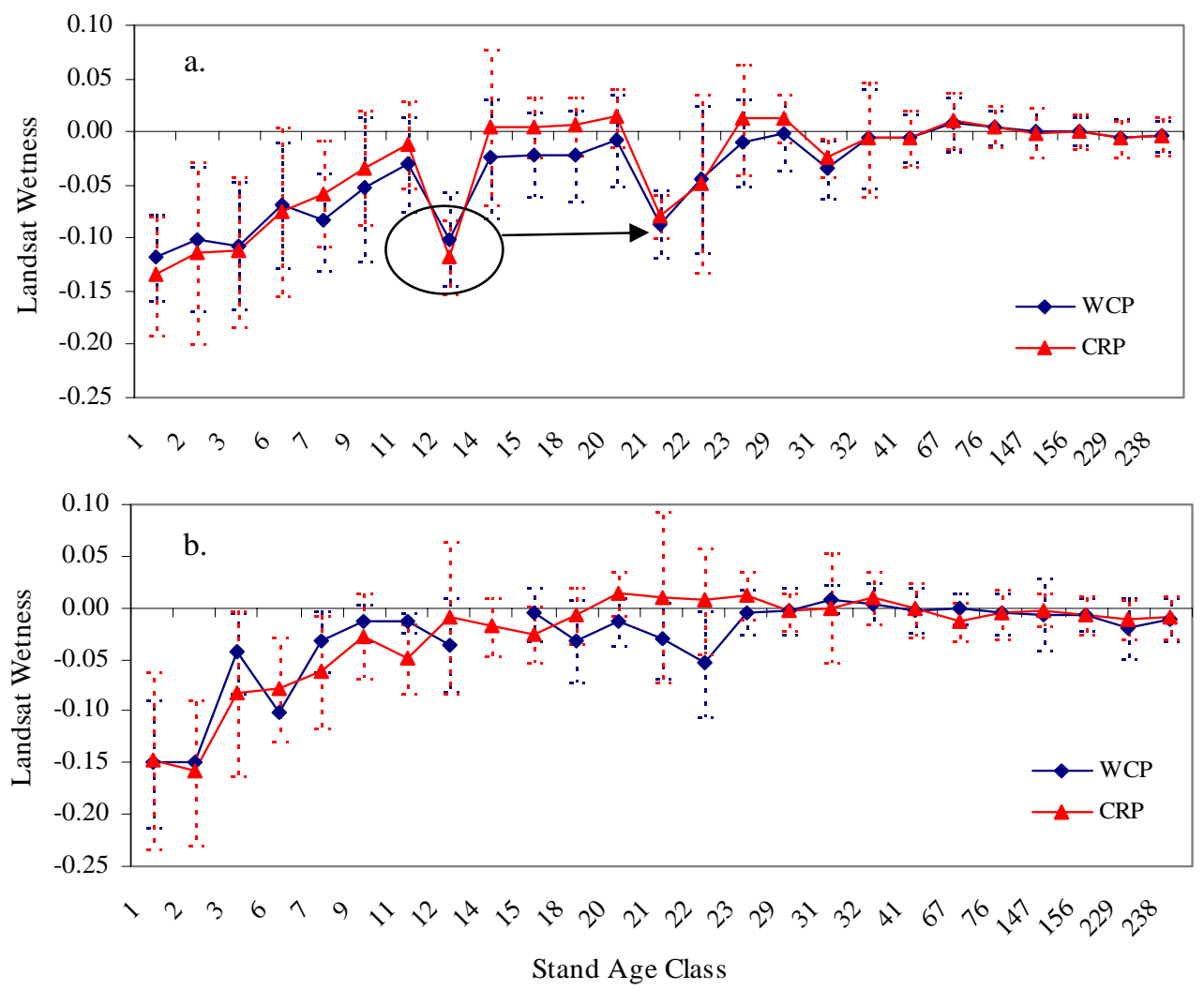

Fig. 4. Landsat wetness trajectories derived using stand age classes from a. Landsat disturbance maps and $b$. inventory plots. Circle indicates spectral shift away from normal forest development. Arrow shows the continued presence of the spectral shift 9-years after it was first detected.

The trajectories developed with the age maps show wetness increases steadily from year one, with some evidence after year 6 that average growth in the CRP is faster (i.e., approaches 0.00 more quickly) than in the WCP. This same age range in the inventory-based trajectories shows a similar increase in wetness, and the ecoregion pattern, although less clear, shows the WCP curve approaching 0.00 more quickly than the CRP. At age 12, the map-based trajectories show a sharp drop in wetness (circled area, Figure 4a), revealing a significant spectral shift away from the typical response of wetness that occurs during normal forest succession. As the map-based wetness trajectories were developed using individual maps that are 9 years a part (1995 and 2004) the same shift in wetness is also seen at age 21 (arrow, 
Figure 4a), indicating the likelihood of permanent land-use change. Based on the stand age map statistics an estimated 13,668 ha of the study area could be affected by the proposed landuse shift. Although this punctuated shift in wetness is not observed in the inventory-based trajectories, approximately 13 plots in the study area went from forest to non-forest designation between the mid-1970's and mid-1980's. This change in plot classification status equates to approximately 36,659 ha of potential land-use change.

\section{DISCUSSION}

\subsection{Per-pixel carbon}

At the local scale, we evaluated the performance of the curve-fit carbon model using pixellevel scatter plots, descriptive statistics and regression diagnostics. Given the various simplifying assumptions of the model (i.e., single successional pathway through Douglas-fir and all harvested stands regrow to new forests) it is not surprising that at the pixel-level the curve-fit model performs only modestly. Sources of potential error in the pixel-level carbon estimates include plot and image coordinate registration, accuracy of stand age maps, accuracy and detail of site index map, curve calibration for Douglas-fir, use of one image date to represent each multi-date inventory period, and the assumption that all recovering forest stands are fully stocked Douglas-fir. We do see evidence that the curve-fit model predicted live forest carbon more accurately (i.e., higher correlation, lower RMSE) in the CRP than in the WCP. It is likely the curve-fit model more accurately predicted live forest carbon in the CRP as it tends to support predominately Douglas-fir stands which grow faster and more consistently (i.e., less variable growth rates) as a result of favorable growing conditions $[12,30]$.

Although the curve-fit model performed better in the CRP, the bias statistics suggested that the model over-predicts live forest carbon in both ecoregions. At the pixel-level, it appears that the curve-fit model suffers from the same asymptotic relationship with biomass that direct empirical models have [4]. Some of the over-prediction is likely the result of using growth curves parameterized specifically for one species (Douglas-fir). Adjusting the $\beta_{1}$ and $\beta_{2}$ parameters does shift the predictions downward reducing the bias (results not presented), however it is a reduction in the residual scatter that is most desired. This might best be accomplished by improving the spatial detail and accuracy of the site index map used to assign the curve-based carbon values. Incorporating Light Detection and Ranging (LiDAR) data could help improve site index estimates at the stand level [53], while the use of physiologically based simulation models such as 3-PG (Physiological Principles in Predicting Growth) [3] might best improve coarse resolution estimates of site index over larger areas. Investigating the impact of using more detailed site index maps derived with the 3-PG simulation model [54] is a focus of future work. The stand-level variability in forest regrowth common too many Pacific Northwest forests is the result of complex interactions among site productivity, climate, geographic gradients and intensive forest management [12,30]. This complex relationship will be difficult to accurately account for with any model, especially one as simple as the curve-fit model. Nonetheless, the results do give merit to the effectiveness of simple land-use accounting approaches even when evaluated at the pixel scale.

\subsection{Study area carbon}

As the pixel-level validation showed that the curve-fit model tended to locally over-predict forest carbon, it is no surprise that the curve-fit model also over-predicted study area live forest carbon. Although in absolute terms this over-estimation is significant (average of 138.32 $\mathrm{Tg}$ per inventory period), the net flux (i.e., difference between inventory periods) estimated by the curve-fit model was found to be well within the standard error of the 
inventory estimates. This is a particularly relevant finding as accurate estimation of the change in live carbon stores is potentially more important than accurately predicting carbon at any one point in time, especially at large spatial scales. This finding also helps provide additional credibility to the live forest carbon flux estimates previously derived with the curve-fit model $[5,7,24]$. For a slightly larger (but overlapping) western Oregon study area, Wallin et al. [24] estimated a sink of live forest carbon of approximately $1.7 \mathrm{Mg} \mathrm{C} \mathrm{ha}^{-1} / \mathrm{yr}$ between 1991 and 1995. This estimate is similar in magnitude to our estimated sink of 1.63 $\mathrm{Mg} \mathrm{C} \mathrm{ha}{ }^{-1} / \mathrm{yr}$ between 1995 and 2004. Although the spatial area of each study is slightly different, our results suggest a similar size sink to that dating back to 1991, possibly resulting from implementation of the Northwest Forest Plan [55].

In addition, we note that our live forest carbon estimates for both inventory periods were derived using the same set of national scale allometric equations [44], thus eliminating unwanted error in our flux calculations due to differences in equation form. FIA typically calculates and reports biomass data using a variety of species specific allometric equations, however as presented here we favor the use of national equations [44] so that derived estimates and their associated errors can be compared in similar units regardless of modeling strategy.

\subsection{Landsat wetness histograms and trajectories}

Direct forest inventories such as FIA are one of the more reliable means from which to base regional and national scale carbon budgets [56,57]. For inventories to be truly effective they must capture the spatial and temporal changes in land-use patterns occurring at the landscape scale. This can be a difficult task in complex landscapes where differences can occur between ecosystems currently on the landscape and those that have been previously cleared [58]. Here we utilized the Tasseled Cap wetness index [25,52] as a proxy measure of forest condition as it responds predictably over the course of forest development and is nearly insensitive to topographic effects $[26,27]$. Although not presented, the relative frequency histograms of wetness confirmed that the inventory plots from both time periods effectively captured the forest conditions found within the full study area. As this was a very general measure, we were interested in a more detailed evaluation of the inventory samples representation of forest change as depicted by the change in spectral wetness over time.

Using both map and FIA-based stand ages we used a chronosequence approach to develop spectral trajectories from which to look for significant deviations away from the normal pattern of forest development. In the map-based trajectories a pronounced spectral shift away from normal forest development was detected at age 12 (Figure 4a). Using the stand age maps (i.e., age class 12), multi-temporal Landsat imagery and high resolution aerial photography (1meter resolution, true color photography from National Agriculture Imagery Program (NAIP) we interpreted this observed shift in wetness as a response to forest conversion along the Willamette valley margins due to urban (e.g., rural homesteads) and agricultural (e.g., crop fields and Christmas tree farms) expansion. As we used a space for time approach, the forest stands that make up age 12 are represented in the trajectories again at age 21(Figure 4a). At age 21 we see that the curves of average wetness have increased only slightly from that of age 12 , indicating that some of the detected shift away from normal forest development is likely a long term change in land-use. This shift in land-use occurred around 1983 (i.e., age 12 in 1995), which coincides with implementation of land-use laws in western Oregon which sought to eliminate housing development on forestland after January 1, 1985 [59]. It is quite possible that a flurry of logging and home construction just prior to the 1985 land-use deadline left a permanent imprint on the landscape. Studies have shown the amount of forest to non-forest land-use conversion in western Oregon was indeed high at this point in time and have since decreased in response to the land-use legislation [60]. Detecting this type of land-use shift is noteworthy as uncertainties associated with rates of land-use change (especially conversion of 
forest to non-forest) contribute more to the uncertainty of carbon flux estimates than do uncertainties in modeling biophysical variables [61].

Although the land-use shift was not observed in the inventory-based trajectories, the inventory data themselves do suggest a considerable change $(\approx 36,659$ ha) in forest to nonforest land-use as 13 plots changed from forest to non-forest designation just prior to the 1985 land-use legislation. While it is not possible to say which estimate of land-use conversion might be more accurate, it should be noted that the difference between the two estimates is rather large $(\approx 22,991 \mathrm{ha})$. One advantage to using the age maps in this context is that areas on the landscape affected by land-use change can be more accurately located and the timing of conversion more precisely pinpointed. On the other hand, pinpointing areas of land-use change directly with FIA plots might be more difficult as the precise plot coordinates are not publicly available and only $10 \%$ of the sample plots are measured each year. For these reasons we support a more synergistic use of field and satellite inventory methods when estimating live forest carbon dynamics at the landscape scale.

\section{CONCLUSION}

As optical satellite data have been shown to have an asymptotic relationship with biomass we tested a highly simplified method that could potentially overcome this limitation. The curvefit models estimates of live forest carbon were evaluated at both the local and landscape scales in western Oregon using two periods of FIA forest inventory data represented by 1995 and 2004 image dates.

At the pixel-level, the curve-fit model performed rather poorly. The model did perform better (i.e., higher correlation, lower RMSE) in the CRP than the WCP, likely the result of faster, less variable growth patterns which have been previously observed for the CRP $[12,33]$. Model predictions for both ecoregions were observed to have large positive bias statistics, indicating over-prediction of low- to mid-range carbon values and under-prediction of high carbon values. The results indicated that the curve-fit predictions displayed the same asymptotic relationship with biomass as direct modeling with Landsat spectral data. Given the simplifying assumptions of the curve-fit model (one successional pathway through Douglas-fir and all disturbed forest stands recover to new forests) it is not surprising that it did not accurately account for the pixel-level variability in forest regrowth commonly observed in Pacific Northwest forests. Nonetheless, the results do give merit to the effectiveness of simple land-use accounting approaches even when evaluated at the pixel scale.

At the landscape scale the curve-fit model also over-predicted study area carbon (average of $138.32 \mathrm{Tg}$ per inventory period). In absolute terms, we found the curve-fit models estimate of net flux (i.e., difference between inventory estimates) to be considerable $(9.12 \mathrm{Tg})$ although well within the standard error of the inventory estimates. In relative terms, we found the net flux to be very similar to the inventory-based estimate ( $7.22 \%$ curve-fit, $7.40 \%$ inventory). This is a particularly relevant finding as accurate estimation of the change in live carbon stores is possibly more important than accurately predicting carbon at one point in time, especially at the landscape scale.

To gauge the sense to which the inventory plots captured the forest conditions in our study area we examined relative frequency histograms of Landsat wetness derived for the full study area and for the inventory plots. Based on shape and magnitude of the histograms we found the field plots from both inventory periods well represented the general forest conditions found in the study area. We also presented wetness trajectories developed using age classes from both the Landsat age maps and from the inventory data. Since wetness responds predictably to structural changes associated with forest growth, we were able to detect a significant shift away from the normal pattern of forest development using the map-based trajectories. This spectral shift, interpreted as forest to non-forest conversion (e.g., 
agricultural and rural expansion), was not observed in the inventory-based trajectories of stand age.

As land-use changes are difficult to detect with any method, we do not wish to imply that the inventory sample did not capture the forest dynamics of the study area, but rather that the synoptic view of Landsat is an effective tool for identifying both the timing and spatial location of forest disturbance and when studied over time, an effective tool for identifying potential land-use conversions. At the landscape scale, the simple Landsat based curve-fit model yielded similar relative change estimates of live forest carbon to those derived with field inventory data. Our evaluation of the curve-fit model gives merit to the application of simple land-use accounting methods for spatially tracking carbon in Pacific Northwest forests. The wetness chronosequence approach should prove useful in quantifying the impact of significant land-use shifts (forest to non-forest conversions) in future applications of the curve-fit model.

\section{Acknowledgments}

We gratefully acknowledge data and financial support provided by the USDA Forest Service Pacific Northwest research station's Forest Inventory and Analysis Program.

\section{References}

[1] C.D. Keeling and T.P. Whorf, "Atmospheric $\mathrm{CO}_{2}$ records from sites in the SIO air sampling network," in Trends: A Compendium of Data on Global Change, Carbon Dioxide Information Analysis Center, Oak Ridge National Laboratory, U.S. Department of Energy, Oak Ridge, TN (2005) http://cdiac.ornl.gov/trends/co2/siomlo.htm

[2] A.M. Solomon, I.C. Prentice, R. Leemans, and W.P. Cramer, "The interaction of climate and land use in future terrestrial carbon storage and release," Water Air Soil Poll. 40, 407-418 (1993).

[3] J.J. Landsberg and R.H. Waring, "A generalized model of forest productivity using simplified concepts of radiation-use efficiency, carbon balance and partitioning," Forest Ecol. Manage. 172, 199-214 (1997).

[4] D.P. Turner, S.V. Ollinger, and J.S. Smith, "Integrating remote sensing and ecosystem process models for landscape-to regional-scale analysis of the carbon cycle," Biosci. 54, 573-584 (2004) [doi:10.1641/00063568(2004)054[0573:IRSAEP]2.0.CO;2].

[5] D.O. Wallin, M.E. Harmon, W.B. Cohen, M. Fiorella, and W.K. Ferrell, "Use of remote sensing to model land use effects on the carbon flux in forests of the Pacific Northwest, USA," in The Use of Remote Sensing in the Modeling of Forest Productivity at Scales from the Stand to the Globe, H.L. Gholz, K. Nakane, and H. Shimoda, Ed., pp. 219-237, Kluwer Academic Publishers, Dordrecht, Netherlands (1996).

[6] M.A. Cairns, P.K. Haggerty, R. Alvarez, B.H.J. DeJong, and I. Olmsted, "Tropical Mexico's recent land-use change: A region's contribution to the global carbon cycle," Ecol. Appl. 10, 1426-1441 (2000) [doi:10.1890/10510761(2000)010[1426:TMSRLU]2.0.CO;2].

[7] W.B. Cohen, M.E. Harmon, D.O. Wallin, and M. Fiorella, "Two decades of carbon flux from forests of the Pacific Northwest," Biosci. 46, 836-844 (1996) [doi:10.2307/1312969].

[8] J.S. Kimball, A.R. Keyser, S.W. Running, and S.S. Saatchi, "Regional assessment of boreal forest productivity using an ecological process model and remote sensing parameter maps," Tree Physio. 20, 761-775 (2000). 
[9] J. Dong, R.K. Kaufmann, R.B. Myneni, C.J. Tucker, P.E. Kauppi, J. Liski, W. Buermann, V. Alexeyev, and M.K. Hughes, "Remote sensing estimates of boreal and temperate forest woody biomass: Carbon pools, sources and sinks," Rem. Sens. Environ. 84, 393-410 (2003) [doi:10.1016/S0034-4257(02)00130-X].

[10] S. Labrecque, R.A. Fournier, J.E. Luther, and D. Piercey, "A comparison of four methods to map biomass from Landsat-TM and inventory data in western

Newfoundland," Forest Ecol. Manage. 226, 129-144 (2006)

[doi:10.1016/j.foreco.2006.01.030].

[11] W.B. Cohen, T.A. Spies, R.J. Alig, D.R. Oetter, T.K. Maiersperger, and M. Fiorella, "Characterizing 23 years (1972-95) of stand replacement disturbance in western Oregon forests with Landsat imagery," Ecosyst. 5, 122-137 (2002)

[doi:10.1007/s10021-001-0060-X].

[12] T.A. Schroeder, W.B. Cohen, and Z. Yang, "Patterns of forest regrowth following clearcutting in western Oregon determined from multi-temporal Landsat data," For. Ecol. Manage. 243, 259-273, (2007) [doi:10.1016/j.foreco.2007.03.019].

[13] D. Lu, "Above-ground biomass estimation using Landsat TM data in the Brazilian Amazon," Int. J. Rem. Sens. 26, 2509-2525 (2005)

[doi:10.1080/01431160500142145].

[14] W.B. Cohen, M. Fiorella, J. Gray, E. Helmer, and K. Anderson, "An efficient and accurate method for mapping forest clearcuts in the Pacific Northwest using Landsat imagery," Photogram. Engin. Rem. Sens. 64, 293-300 (1998).

[15] D.J. Hayes and S.A. Sader, "Comparison of change-detection techniques for monitoring tropical forest clearing and vegetation regrowth in a time series," Photogram. Engin. Rem. Sens. 67, 1067-1075 (2001).

[16] W.B. Cohen and S.N. Goward, "Landsat's role in ecological applications of remote sensing," Biosci. 54, 535-545 (2004) [doi:10.1641/00063568(2004)054[0535:LRIEAO]2.0.CO;2].

[17] S.P. Healey, Z. Yang, W.B. Cohen, and D.J. Pierce, "Application of two regressionbased methods to estimate the effects of partial harvest on forest structure using Landsat data," Rem. Sens. Environ. 101, 115-126 (2006)

[doi:10.1016/j.rse.2005.12.006].

[18] R.E. Kennedy, W.B. Cohen and T.A. Schroeder, "Trajectory-based change detection for automated characterization of forest disturbance dynamics," Rem. Sens. Envion. 110, 370-386 (2007) [doi:10.1016/j.rse.2007.03.010].

[19] F.J. Richards, "A flexible growth function for empirical use," J. Exp. Bot. 10, 290300 (1959) [doi:10.1093/jxb/10.2.290].

[20] L. Hegler, "A method for constructing site-index curves from stem analysis," For. Chron. 21, 11-15 (1996).

[21] M.E. Harmon, "Carbon sequestration in forests: Addressing the scale question," $J$. For. 99, 24-29 (2001).

[22] J.E. Janisch and M.E. Harmon, "Successional changes in live and dead wood carbon stores: implications for net ecosystem productivity," Tree Phys. 22, 77-89 (2002).

[23] A.M. Law and W.D. Kelton, Simulation Modeling and Analysis, McGraw-Hill, New York, NY (1991).

[24] D.O. Wallin, M.E. Harmon, and W.B. Cohen, "Modeling regional-scale carbon dynamics in Pacific Northwest forests: 1072-95," in Carbon Dynamics of Two Forested Regions: Northwestern Russian and the Pacific Northwest, O. Krankina and M.E. Harmon, Ed., pp. xx-xx, Springer-Verlag, New York, NY (in press).

[25] E.P. Crist and R.C. Cicone, "A physically-based transformation of Thematic Mapper data-the TM Tasseled Cap,” IEEE Trans. Geosci. Rem. Sens. 22, 256-263 (1984) [doi:10.1109/TGRS.1984.350619]. 
[26] W.B. Cohen and T.A. Spies, "Estimating structural attributes of Douglas-fir/Western hemlock forest stands from Landsat and SPOT imagery," Rem. Sens. Environ. 41, 117, (1992) [doi:10.1016/0034-4257(92)90056-P].

[27] W.B. Cohen, T.A. Spies, and M. Fiorella, "Estimating the age and structure of forests in a mutlti-ownership landscape of western Oregon, U.S.A.," Int. J. Rem. Sens. 16, 721-746 (1995) [doi:10.1080/01431169508954436].

[28] J.M. Omernik, "Ecoregions: a spatial framework for environmental management," in Biological Assessment and Criteria, W.S. Davis and T.P. Simon, Ed., pp. 49-62, Lewis Publishers, Boca Raton, FL (1995).

[29] J. Franklin and C.T. Dyrness, Natural Vegetation of Oregon and Washington, $2^{\text {nd }}$ ed., Oregon State University Press, Corvallis, OR (1988).

[30] Z. Yang, W.B. Cohen, and M.E. Harmon, "Modeling early forest succession following clear-cutting in western Oregon," Can. J. For. Res. 35, 1889-1900 (2005) [doi:10.1139/x05-132].

[31] R.A. Birdsey and H.T. Shreuder, "An overview of the forest inventory and analysis estimation procedures in the eastern United States - with an emphasis on the components of change," GRT-RM-214, USDA Forest Service General Technical Report (1992).

[32] W.A. Bechtold and P.L. Patterson, "The enhanced forest inventory and analysis program - National sampling design and estimation procedures,' GTR-SRS-80, USDA Forest Service General Technical Report (2005).

[33] B. Hiserote and K. Waddell, The PNW-FIA Integrated Database User Guide Version 1.4, USDA Forest Service Pacific Northwest Research Station, Portland, OR (2004).

[34] R.E. McRoberts, "A model-based approach to estimating forest area," Rem. Sens. Environ. 103, 56-66 (2006) [doi:10.1016/j.rse.2006.03.005].

[35] J.L. Ohmann and M.J. Gregory, "Predictive mapping of forest composition and structure with direct gradient analysis and nearest-neighbor imputation in coastal Oregon, USA," Can. J. Forest Res. 32, 725-741 (2002) [doi:10.1139/x02-011].

[36] W.B. Cohen, T.K. Maiersperger, T.A. Spies, and D.R. Oetter, "Modeling forest cover as continuous variables in a regional context with Thematic Mapper data," Int. $J$. Rem. Sens. 22, 2279-2310 (2001) [doi:10.1080/014311601300229827].

[37] M. Moeur, T.A. Spies, M. Henstrom, J.R. Martin, J. Alegria, J. Browing, J. Cissel, W.B. Cohen, T. Demeo, S. Healey, and R. Warbington, "Status and trend of latesuccessional and old-growth forests under the Northwest Forest Plan," GTR-PNW646, USDA Forest Service General Technical Report (2005).

[38] S. Lennartz, "Oregon forest land change mapping," Sanborn Mapping Solutions, Portland, OR (2005).

[39] R.H. Waring, K.S. Milner, W.M. Jolly, L. Phillips, and D. McWethy, "Assessment of site index and forest growth capacity across the Pacific and Inland Northwest U.S.A. with MODIS satellite-derived vegetation index," For. Ecol. Manage. 228, 285-291 (2006) [doi:10.1016/j.foreco.2006.03.019].

[40] L.A. Isaac, Better Douglas-fir Forests From Better Seed, University of Washington Press, Seattle, WA (1949).

[41] T.A. Schroeder, W.B. Cohen, C. Song, M.J. Canty, and Z. Yang, "Radiometric correction of multi-temporal Landsat data for characterization of early successional forest patterns in western Oregon," Rem. Sens. Environ. 103, 16-26 (2006) [doi:10.1016/j.rse.2006.03.008].

[42] M.J. Canty, A.A. Nielsen, and M. Schmidt, "Automatic radiometric normalization of multitemporal satellite imagery," Rem. Sens. Environ. 91, 441-451 (2004)

[doi:10.1016/j.rse.2003.10.024]. 
[43] E.F. Vermote, D. Tanre, J.L. Deuze, M. Herman, and J.J. Morcrette, "Second simulation of the satellite signal in the solar spectrum, 6S: an overview," IEEE Trans. Geosci. Rem. Sens. 35, 895-934 (1997) [doi:10.1109/36.581987].

[44] J.C. Jenkins, D.C. Chojnacky, L.S. Heath, and R.A. Birdsey, "National-scale biomass estimators for United States tree species," For. Sci. 49, 12-35 (2003).

[45] M.J. Swift, O.W. Heal, and J.M. Anderson, Decomposition in Terrestrial Ecosystems, University of California Press, Berkely, CA (1979).

[46] C. Song, C.E. Woodcock, K.C. Seto, M. Pax-Lenney, and S.A. Macomber, "Classification and change detection using Landsat TM data: when and how to correct atmospheric effects," Rem. Sens. Environ. 75, 230-244 (2001) [doi:10.1016/S0034-4257(00)00169-3].

[47] M.E. Harmon, B. Marks, and R.N. Hejeebu, "A User's Guide to STANDCARB Version 1.0: A Model to Simulate the Carbon Stores in Forest Stands," (1996) http://www.fsl.orst.edu/lter/pubs/webdocs/models/standcar.cfm .

[48] C.C. Grier and R.S. Logan, "Old-growth Pseudotsuga menziesii communities of a western Oregon watershed: biomass distribution and production budgets," Ecol. Mono. 47, 373-400 (1977) [doi:10.2307/1942174].

[49] M.E. Harmon, J.F. Franklin, F.J. Swanson, P. Sollins, S.V. Gregory, J.D. Lattin, N.H. Anderson, S.P. Cline, N.G. Aumen, J.R. Sedell, G.W. Lienkaemper, K. Cromack Jr., and K.W., Cummins, "Ecology of coarse woody debris in temperate ecosystems," Rec. Adv. Ecol. Res. 15, 133-302 (1986).

[50] E.H. Smithwick, M.E. Harmon, S.M. Remillard, S.A. Acker, and S.F. Franklin, "Potential upper bounds of carbon stores in forests of the Pacific Northwest," Ecol. Appl. 12, 1303-1317 (2002) [doi:10.1890/10510761(2002)012[1303:PUBOCS]2.0.CO;2].

[51] R.O. Curtis, G.W. Clendenen, D.L. Reukema, and D.J. DeMars, "Yield tables for managed stands of coast Douglas-fir," GTR-PNW-135, USDA Forest Service General Technical Report (1982).

[52] E.P. Crist, "A TM tasselled cap equivalent transformation for reflectance factor data," Rem. Sens. Environ. 17, 301-306 (1985) [doi:10.1016/0034-4257(85)90102-6].

[53] D. Gatziolis, "Lidar-derived site index in the U.S. Pacific Northwest - Challenges and opportunities," Proc. SilviLaser, 136-143 (2007).

[54] J.J. Swenson, R.H. Waring, W. Fan, and N. Coops, "Predicting site-index with a physiologically based growth model across Oregon, USA," Can. J. For. Res. 35, 1697-1707 (2005) [doi:10.1139/x05-089].

[55] Forest Ecosystem Management An Assessment Team, "Report of the Forest Ecosystem Management Assessment Team,” USDA Forest Service, Ogden UT, (1993).

[56] D.P. Turner, G.J. Koerper, M.E. Harmon, and J.J. Lee, "A carbon budget for forests of the conterminous United States," Ecol. Appl. 5, 421-436 (1995) [doi:10.2307/1942033].

[57] J.C. Jenkins, R.A. Birdsey, and Y.Pan, "Biomass and NPP estimation for the MidAtlantic region (USA) using plot-level forest inventory data," Ecol. Appl. 11, 11741193 (2001) [doi:10.1890/1051-0761(2001)011[1174:BANEFT]2.0.CO;2].

[58] R.A. Houghton, K.T. Lawrence, J.L. Hackler, and S. Brown, "The spatial distribution of forest biomass in the Brazilian Amazon: a comparison of estimates," Glb. Chng. Bio. 7, 731-746 (2001) [doi:10.1046/j.1365-2486.2001.00426.x].

[59] Oregon Administrative Rules, "Dwellings in Forest Zones," OAR 660-006-0027, Secretary of State, Salem, OR, (2007).

[60] D.L. Azuma, K.R. Birch, A.A. Herstrom, J.D. Kline, and G.J. Lettman, "Forests, Farms, \& People: Land use change on non-federal land in western Oregon, 19732000," Oregon Department of Forestry, Salem, OR, 1-52 (2002). 
[61] R.A. Houghton and C.L. Goodale, "Effects of land-use change on the carbon balance of terrestrial ecosystems," in Ecosystems and Land Use Change, R.H. DeFries, G.P. Asner and R.A. Houghton, Ed., pp. 85-98, American Geophysical Union Press, Washington, D.C. (2004). 